\title{
AN INTERPRETATION OF THE GOLDEN GROVE GRAVITY HIGH IN SOUTHERN NEW BRUNSWICK
}

\author{
V.K. GUPTA \\ Ontario Geological Survey, 77 Grenville Street, Toronto, Ontario
}

K.B.S. Burke

Geology Department, University of New Brunswick, Fredericton, New Brunswick

The Golden Grove gravity high in southern New Bmunsick is associated with mafic intmisive rocks ranging from diorite to gabbro. The anomaly was interpreted with the aid of an iterative two-dimensional gravity modelling program used in conjunction with a non-linear optimization computer package MINUIT. For minimization, the simplex method of Nelder and Mead and the variable metric method of Fletcher were used with constraint. The optimum causative body parameters indicate that the mafic intmisive mass is a sizl-like (tabular) body, having a depth extent of about $l \mathrm{~km}$, with outward dipping contacts.

\section{INTRODUCTION}

The results of the gravity survey carried out by Burke (1975) over the northwestern part of the Caledonia area in southern New Brunswick indicate a large positive gravity anomaly with steep gradients. A large mafic intrusive body is exposed at the surface, and its centre coincides with the gravity anomaly peak. It has been suggested by Pajari and Rast (1975, Oral Communication) that the rock outcrops comprising this Golden Grove intrusion vary in composition from diorites through gabbro to metagabbros. Therefore the mostly likely explanation for the gravity high are the mafic intrusives which outcrop randomly at the surface. The gravity anomaly, which is there called the Golden Grove gravity high, has a coincident aeromagnetic high (Geological Survey of Canada, 1960).

The objective of the present study was to determine an optimum solution of the Golden Grove gravity high in terms of the underlying mafic intrusion, using iterative non-linear optimization methods. The resultant optimum gravity models are then compared to the latest geological information for the area (Ruitenberg et al 1975).

The term optimization refers to locating maxima or minima of functions of a number of variables that often have to satisfy a set of auxiliary equations, with or without constraints. various optimization methods have been given in the literature to locate these extremes depending upon the nature of the problem involved. In two-dimensional gravity and magnetic interpretation optimization techniques have been used recently by Al Chalabi (1971a, b, 1970), and Westbrook (1974).

In this study the gravity modelling was carried out using a computer package MINUIT (James and Roos 1976), which allows a user to minimize a function of several independent variables. The function, $f$, to be minimized is determined through a user-provided subroutine that calculates a twodimensional body model that will give a fit to an observed gravity anomaly. The paramters $(x$ and $z$ coordinates of the body, the background gravity of the form $R_{0}+R_{x} x$, and the density) can be bounded if desirable, within a lower and upper limit, or kept constant if their values are known from surface geology, drilling or seismic data.
The main advantage of using iterative optimization techniques for modelling, over trial and error methods, is that reasonably good models may be obtained with a relatively small effort on the part of the geophysicist.

\section{OPTIMIZATION}

In the real geological situation, the causative bodies are usually more heterogeneous than that represented by the gravity model. We normally seek an optimum solution of the theoretical gravity model parameters by minimizing an objective function $f(x), x=x, x,--, x p$. The non-linear objective function $f(x)$ which is to be minimized can then be defined in a least squares sense as

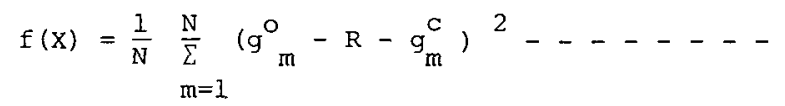

where $\mathrm{g}^{\circ}=$ observed gravity

$\mathrm{R}$ = regional background gravity of the form $R_{0}+R_{1} x$

$g^{C}=$ computed gravity

and $\mathrm{N}=$ number of observations.

Thus the mean value of the squared residual gravity is minimized.

The gravitational attraction for two-dimensional bodies having infinite strike length can be calculated from the expression for an $\mathrm{N}$-sided polygon at any point $m$ by Nagy (1964):

$$
\begin{aligned}
& g_{m}^{c}=2 \gamma \rho \sum_{i=1}^{n} c / \Delta x^{2}+\Delta z^{2}\left(\frac { 1 } { 2 } \Delta z \operatorname { l n } \left(\left(x^{2}+z_{i+1}^{2}\right) /\right.\right. \\
& \left.\left.\left(x_{i}^{2}+z_{i}^{2}\right)\right)+\Delta x\left(\operatorname{arctg}\left(x_{i+1} / z_{i+1}\right)-\operatorname{arctg}\left(x_{i} / z_{i}\right)\right)\right) \\
& \cdots(2)
\end{aligned}
$$$$
\text { where } \begin{aligned}
c= & x_{i} z_{i+1}-x_{i+1} z_{i} \\
\Delta \dot{x}= & x_{i+1}-x_{i} \\
\Delta z= & z_{i+1}-z_{i} \\
\gamma= & \text { gravitational constant } \\
\rho= & \text { density contrast and } \\
\left(x_{i}, z_{1}\right)= & \text { pairs of coordinates to each of the } \\
& \text { nertices with respect to point } m .
\end{aligned}
$$ 


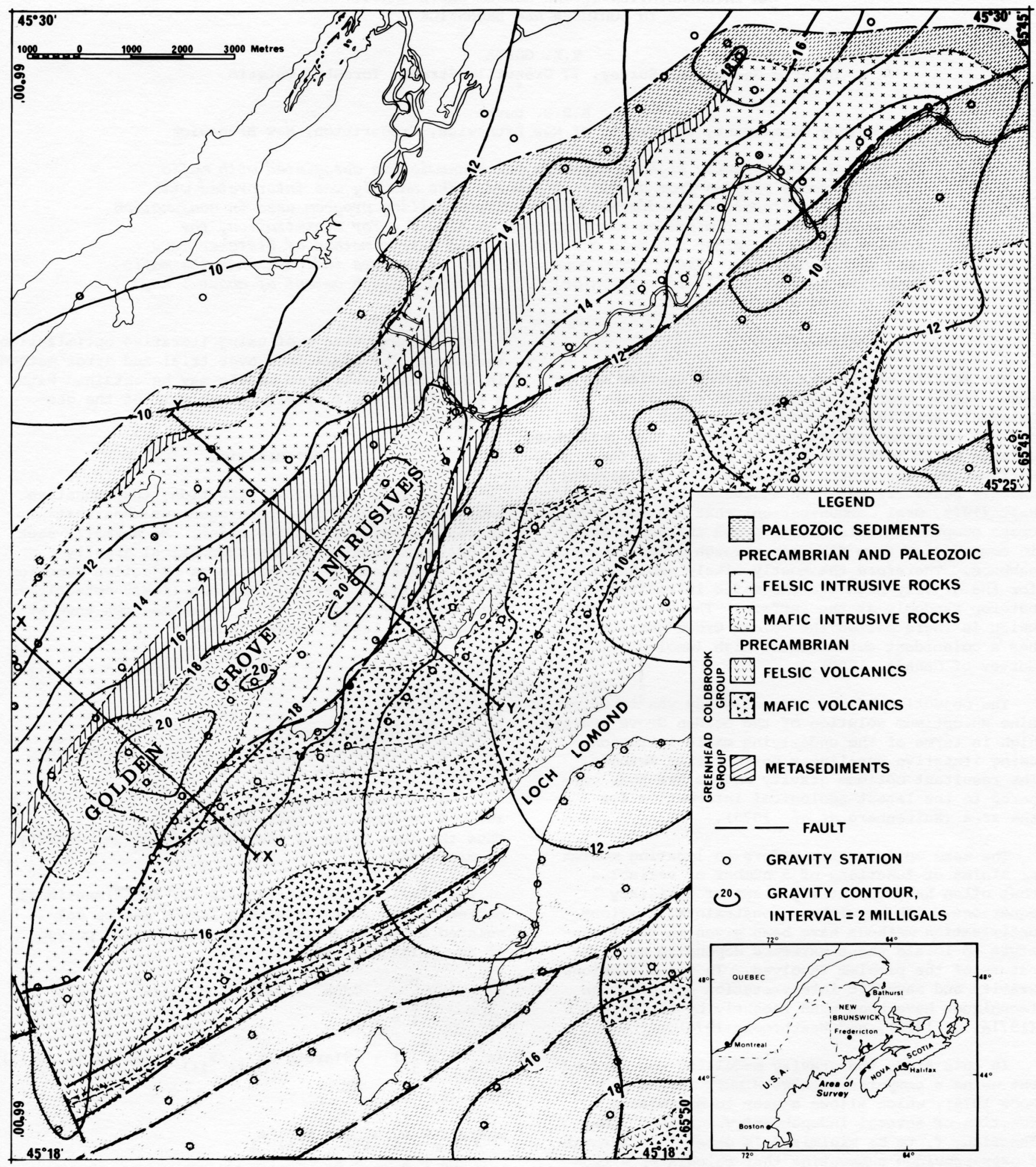

FIG. I An interpretation of the Golden Grove gravity high in Southern N.B. 

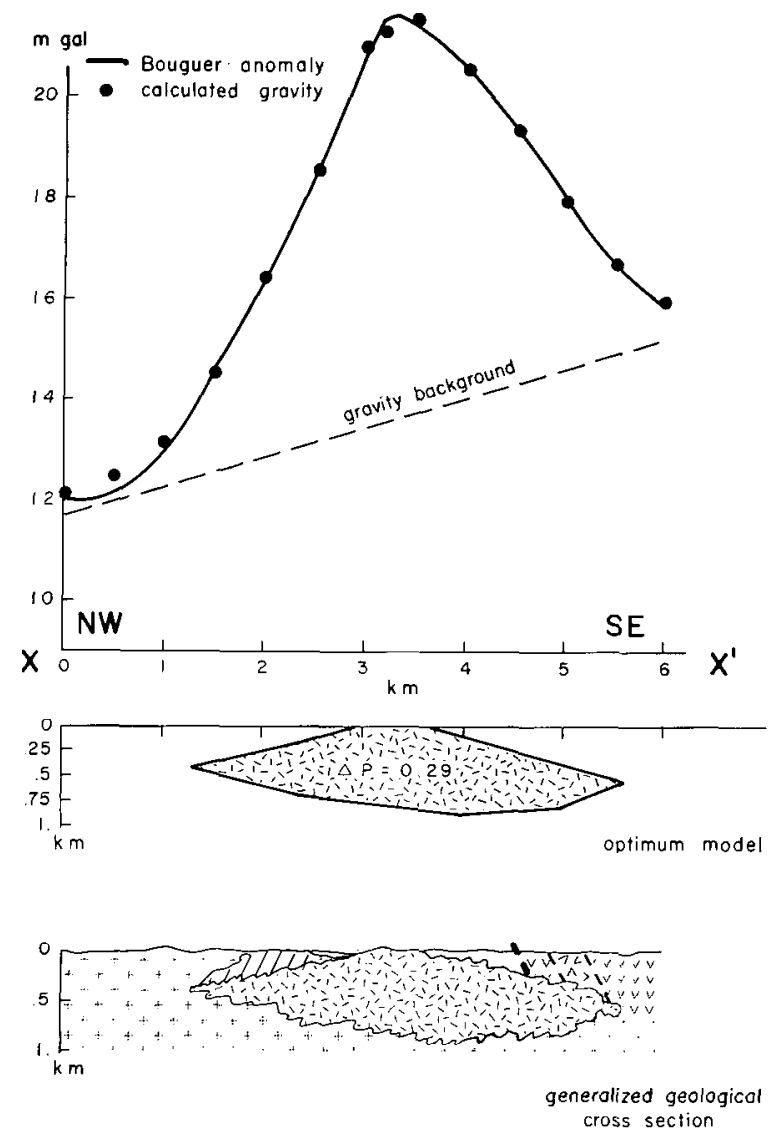

FIG. 2 An interpretation of the Golden Grove gravity high in Southern N.B. (Profile $X-X^{\prime}$ )

Since $g_{m}^{c}$ is a function of the model coordinates $\left(x_{1}, x_{2},-\cdots, x_{n}, z_{1}, z_{2}, \cdots, z_{n}\right)$ and the density contrast $\rho$, the objective function is of the form $f=f\left(x_{1}, x_{2}, \cdots, x_{n}, z_{I}, \cdots, z_{n}, \rho, R_{0}, R_{I}\right)$, which is a function defined over a $2 n+3$ dimensional hyperspace.

\section{INTERPRETATION}

The closed Bouguer gravity high (Fig. I) is approximately $13 \mathrm{~km}$ long and $3 \mathrm{~km}$ wide with an amplitude of about 9 mgals. Because many of the elevations of gravity stations were determined using altimeters, individual gravity values may contain errors of up to $+0.5 \mathrm{milligal}$. The simple Bouguer anomalies, contoūred on a 2-milligal interval, are shown superimposed upon a geological map (in Figure 1).

The geological map shows the area of the anomaly to be partly underlain by Greenhead Group metasediments, felsic and mafic intrusives, and coldbrook Group volcanic rocks. The gravity high has
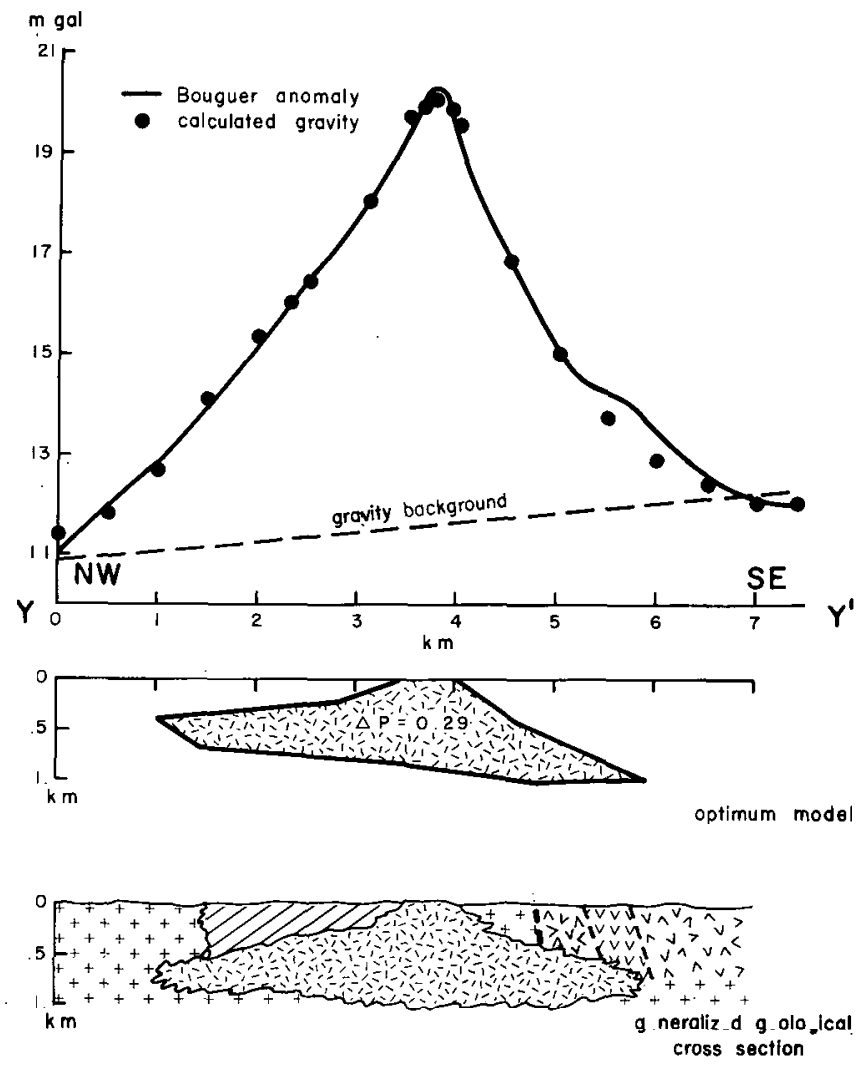

FIG. 2 An interpretation of the Golden Grove gravity high in Southern N.B. (Profile $Y-Y^{\prime}$ )

a corresponding aeromagnetic high with amplitudes ranging from 500 to 800 gammas along the axis of the anomaly. Both the gravity and magnetic anomalies have northeasterly trends which are consistent with the regional geological trends of the northern Appalachians.

The density measurements taken in this area (Gupta and Bruke 1977) indicate almost şimilar densities for metasediments $\left(2.63, \mathrm{gm} / \mathrm{cm}^{3}\right)$, coldbrook felsic volcanics $\left(2.6 \mathrm{gm} / \mathrm{cm}^{3}\right)$, felsic intrusiye rocks $\left(2.6 \mathrm{gm} / \mathrm{cm}^{3}\right)$. A density of 2.9 $\mathrm{gm} / \mathrm{cm}$ was measured for the mafic intrusive rocks. Therefore, according to the measured surface densities, a density contrast in the range 0.27 to $0.3 \mathrm{gm} / \mathrm{cm}^{3}$ should account for this gravity anomaly provided the same density contrast exists at depth.

Two gravity profiles $\mathrm{X}-\mathrm{X}^{\prime}$ and $\mathrm{Y}-\mathrm{Y}^{\prime}$ (Fig. 2) approximately $5 \mathrm{~km}$ apart and perpendicular to the Golden Grove gravity high were chosen for modelling. Since reasonable starting values of the causative body parameters could be estimated from the geo- 
logical knowledge of the area, the Monte Carlo optimization method of MINUIT was not used. On both profiles the outcrop location of the mafic intrusives was taken from the geological map; thus. at these locations $x$ and. $z$ vertices of the body were kept constant. The variable parameters were pairs of vertices of the causative body, the background gravity of the form $R_{0}+R_{1} x$ and the density. It was assumed that the causative body was uniform density contrast with the surrounding rocks, that was constrained between the range $0.27 \mathrm{~g} / \mathrm{cm}$ to $0.30 \mathrm{~g} / \mathrm{cm}^{3}$.

\section{DISCUSSION}

For both profiles, the Simplex method by Nelder and Mead (1965) was used initially to get into the region of the minimum. The variable metric method by Fletcher (1970) was then used to obtain the final solution. We assume that the final solution is obtained when the standard error and the maximum deviation (between the observed and the calculated anomaly) were both equal to or smaller than the measurement uncertainty $f-0.5 \mathrm{mgal}$ in this study).

The resultant optimal body shapes obtained for the two gravity profiles $X-X^{\prime}$ and $Y-Y^{\prime}$ are shown in Figure 2. For profile $X-X^{\prime}$, the standard error is $0.196 \mathrm{mgal}$, the coefficient of correlation 0.999 , and the maximum deviation is $0.42 \mathrm{mgal}$. Similarly for profile $Y-Y^{\prime}$, the standard error is $0.194 \mathrm{mgal}$, the coefficient of correlation 0.998 , and the maximum deviation is $0.42 \mathrm{mgal}$. Thus a good fit has been obtained between the observed and the calculated gravity anomalies as evident from their small residuals. It should be mentioned that the local interference from nearby shallow mafic volcanics on the south-east flank of the anomaly, on profile $Y-Y^{\prime}$ was filtered out prior to optimization.

The computed models have their top at or near to the ground surface and this is in conformity with the geological information that the mafic intrusives outcrop at several places. The bottom surfaces of the models are also calculated and shown. The causative bodies are thickest in the centre, having a thickness of about $1 \mathrm{~km}$.

The results of interpretation by optimization methods show that the calculated shapes of the optimal models (Fig. 2) from two profiles are similar and both have outward dipping contacts. The shape and small calculated depth extent $(1 \mathrm{~km})$ suggests that the northeasterly trending Golden Grove intrusive sheet is a sill-like structure, which has a strike length of more than $13 \mathrm{~km}$. The optimum density contrast values of $0.29 \mathrm{~g} / \mathrm{cm}^{3}$ for both models are within the range of the actual density contrast of 0.27 to $0.3 \mathrm{~g} / \mathrm{cm}^{3}$ obtained from surface rock density measurements.

The modelling procedure is made simpler and less time consuming using optimization techniques. The above two models were obtained in a matter of a few hours of geophysicist's time including the data preparation time. It took less than 25 seconds of CPU time (on IBM 370-168) for each profile, and the optimum models obtained are geologically reasonable.

\section{ACKNOWLEDGEMENTS}

We are thankful to A.K. Goodacre who read an early manuscript and offered constructive criticism. R. McCulloch assisted in the drafting of the diagrams.

\section{REFERENCES}

AL-CHALABI, M. 1970. Interpretation of two-dimensional magnetic profiles by non-linear optimization. Boll. Geof. Teor. Appl., 12, pp. 3-20.

AL-CHALABI, M. 1971 (a). Some studies relating to non-uniqueness in gravity and magnetic inverse problems. Geophysics, 36, pp. 835-855.

AL-CHALABI, M. 1971 (b). Interpretation of gravity anomalies by non-linear optimization. Geophysical Prospecting, 20, pp. 1-16.

BURKE, K.B.S. 1975. Bouguer Anomaly Map, Loch Lomond West Sheet, Plate $75-2$, New Brunswick, Department of Mineral Resources.

FLETCHER, R. 1970. A new approach to variable metric algorithms. Computer Journal, 13, p. 317.

GEOLOGICAL SURVEY OF CANADA 1960. Geophysics Paper 776, Ottawa, Canada.

GUPTA, V.K. and BURKE, K.B.S. 1977. Density and magnetic susceptibility measurements in southeastern New Brunswick. Canadian Journal of Earth Sciences, 14, pp. 128-132.

JAMES, F. and ROOS, M. 1976. MINUIT. A system for function minimization and analysis of the parameter errors and correlations. Long write-up. CERN Computer Centre.

NAGY, D. 1964. The gravitational effect of twodimensional masses of arbitrary cross-section. Ottawa, Dom. Obs., Gravity Div., unpub. manuscript.

NELDER, J.A. and MEAD, R. 1965. A simplex method for function minimization. The Computer Journal, 7, pp. 308-313.

RUITENBERG, A.A., GILES, P.S., VENUGORAL, D.V., BUTTIMER, S.M., MCCUTCHEON, S.R. and CHANDRA, J. 1975. Geological maps to accompany report geology and mineral deposits Caledonia area. New Brunswick, Dept. Natural Resources and Canada, Dept. Regional Economic Expansion.

WESTBROOK, G.K. 1974. The South Harris magnetic anomaly. Proc. Geol. Asso., 85, pp. 1-12. 